\title{
西双版纳地区森林变化碳效应与生态效益评估
}

\author{
刘桂芳 ${ }^{1,2}$, 关瑞敏 ${ }^{1}$, 夏梦琳 ${ }^{1}$, 卢鹤立 ${ }^{1,2,3,4, *}$, 徐 明 ${ }^{1,2,3,4}$, 郑 辉 ${ }^{1,2,3}$ \\ 1 河南大学地理与环境学院/河南大学黄河文明与可持续发展研究中心暨黄河文明省部共建协同创新中心, 开封 475004 \\ 2 黄河中下游数字地理技术教育部重点实验室(河南大学)/河南大学环境与规划国家级实验教学示范中心, 开封 475004 \\ 3 河南省地球系统观测与模拟重点实验室,开封 475004 \\ 4 河南大别山森林生态系统国家野外科学观测研究站,开封 475004
}

摘要:减少发展中国家因森林砍伐与森林退化导致的碳排放和保持碳储量 (REDD+), 不仅能减少因森林砍伐和森林退化造成 的碳排放,而且还可以带来其它生态效益, 如减缓森林破碎化、保护生物多样性和增强水土保持功能等。以中国的西双版纳地 区为研究区域, 以毁林最严重的 1976-2007 年为 REDD+基线,基于卫星影像,并结合植被指数,提取了研究区的土地利用变化 信息。基于 IPCC 温室气体清单方法,计算了研究区的森林碳储量变化。在此基础上,对 REDD+的碳汇效益和生态效益进行了 系统综合评估。结果显示: (1) 1976-2007 年间天然林碳储量从占总碳储量的 78.24\%减少至 50.52\%, 这是造成西双版纳地区 碳储量减少的主要原因。(2) 1976-2007 年, 天然林的斑块数量和平均最近邻距离分别增加了 $120.00 \%$ 和 $25.21 \%$, 平均斑块面 积下降了 $71.98 \%$, 说明天然林的破碎化程度加剧。从研究区整体景观格局来看, 斑块数量、Shannon 多样性指数和 Shannon 均 一性指数分别增加了 $8.16 \% 、 51.39 \%$ 和 $34.07 \%$; 与此同时,平均斑块面积和景观内聚力指数分别下降了 $26.26 \%$ 和 $2.13 \%$, 表明 研究区整体景观格局朝破碎化方向发展,这和碳排放的增加相一致。(3)该区的土壤侵蚀程度逐年加剧, 并与碳储量的减少密 切相关。分析表明,土壤侵蚀剧烈的区域,其平均碳排放也相对较高。1999 年到 2007 年间,剧烈侵蚀区域的平均碳排放是轻度 侵蚀区域的 6 倍多。这些结果说明:如果 REDD+政策得以实施,不仅能减少因毁林和森林退化导致的碳排放,而且能带来高的 生态效益。从这个角度出发, REDD+的本质可以认为是以“增汇”或“减排”为主导功能, 同时提升生态效益的一种管理方式。

关键词:REDD+效益; 毁林; 碳排放; 西双版纳

\section{Comprehensive assessment on both carbon and ecosystem-based benefits from Xishuangbanna's tropical forests changes}

\footnotetext{
LIU Guifang ${ }^{1,2}$, GUAN Ruimin ${ }^{1}$, XIA Menglin ${ }^{1}$, LU Heli ${ }^{1,2,3,4, *}$, XU Ming ${ }^{1,2,3,4}$, ZHENG Hui ${ }^{1,2,3}$

1 College of Geography and Environmental Science/ Collaborative Innovation Center on Yellow River Civilization \& Key Research Institute of Yellow River Civilization and Sustainable Development, Henan University, Kaifeng 475004, China

2 Key Laboratory of Geospatial Technology for the Middle and Lower Yellow River Regions ( Henan University), Ministry of Education/National Demonstration Center for Environment and Planning, Henan University, Kaifeng 475004, China

3 Henan Key Laboratory of Earth System Observation and Modeling, Henan University, Kaifeng 475004, China

4 Henan Dabieshan National Field Observation and Research Station of Forest Ecosystem, Henan University, Kaifeng 475004, China
}

\begin{abstract}
The REDD + partnership works to promote the reduction of greenhouse gas (GHG) emissions by reducing emissions from deforestation and forest degradation in the developing countries through positive incentives and conversation of forest carbon stocks. It is regarded as an essential component of the post-2012 climate regime to stabilize GHG emissions and engage the developing countries in worldwide mitigation endeavors. If cost-efficient carbon benefits can be achieved
\end{abstract}

基金项目:国家自然科学基金项目(42071267，41371525) ; 河南省高校科技创新团队支持计划(21IRTSTHN008)

收稿日期:2020-03-29; 网络出版日期:2021-10-11

*通讯作者 Corresponding author.E-mail: luheli@ henu.edu.cn 
through REDD+, increases in atmospheric $\mathrm{CO}_{2}$ concentrations could be slowed, effectively buying much needed time for countries to move to lower emissions technologies. We chose tropical forests in Xishuangbanna of China as our study area and took the most severe deforestation from 1976 to 2007 as the baseline of REDD+. Land use information was obtained through the combination of Landsat TM images and Normalized Difference Vegetation Index masks. Forest carbon storage change in the study area was firstly calculated based on IPCC methodology. Secondly ecosystem-based benefits from REDD+ were assessed systematically. Our results showed that from 1976 to 2007, the natural forest carbon storage decreased from $78.24 \%$ to $50.52 \%$ of total carbon storage, which was the main reason for the reduction of carbon storage in Xishuangbanna. At the meantime, significant degradation of ecosystem services emerged. This was demonstrated by two important indicators: forest fragmentation and soil erosion. For example, from 1976 to 2007 the percentage change in the carbon stocks was $1.4 \%$, accompanying with increasing $8.16 \%$ in number of patches, $51.39 \%$ in Shannon's diversity index and $34.07 \%$ in shannon's evenness index. Meanwhile, mean path area and patch cohesion index decreased by $26.26 \%$ and $2.13 \%$, respectively. It suggested that the forest ecosystem was changing in both carbon storage and forest landscape structure. The number of patches and average nearest neighbor distance of natural forest increased by $120.00 \%$ and $25.21 \%$, respectively, and the average patch area decreased by $71.98 \%$, indicating the degree of exacerbated fragmentation in natural forest. In this sense, carbon emission and forest fragmentation were well integrated. Furthermore, we investigated relationship between carbon emission and soil erosion and high correlation was found. For example, carbon emissions which accounted for $45 \%$ of the total located in the high erosion area, which is $18 \%$ of the whole study area. As a result, when forests that would have been lost or degraded are retained or restored through REDD+, they deliver 'multiple benefits' in addition to protecting or enhancing carbon stocks. These ecosystem-based benefits may include conservation of forest biodiversity, water regulation, soil conservation, timber, forest foods and other non-timber forest products, most of which have been demonstrated or proved in this study. By securing benefits beyond carbon, REDD + has the potential to encourage countries to realize a broader range of values.

Key Words: REDD+ benefits; deforestation; carbon emissions ; Xishuangbanna

气候变化已经成为当今人类关注的最重要话题之一, 人类活动导致的二氧化碳浓度增加是引起气候变化 的一个重要因素 ${ }^{[1]}$ 。相对于温带和寒带森林, 热带雨林植被碳储量更高, 因而, 热带雨林在应对全球二氧化 碳浓度增加方面扮演着关键性角色 ${ }^{[2-3]}$ 。目前, 热带雨林因森林砍伐导致的碳排放已占全球总温室气体排放 量的 $20 \%$, 远远超过了交通部门碳排放量的占比。然而, 由于核定和监测问题, 以稳定温室气体浓度、实现全 球碳减排为目标的京都议定书, 却并没有涉及到这个方面。因此,除非在国际减排框架中纳人热带雨林地区, 全球温室气体减排目标将不会最终实现 ${ }^{[4-7]}$ 。基于此, 减少发展中国家森林砍伐和退化而降低温室气体排放 的机制在气候变化谈判中逐渐得到发展。2012 年 12 月,在多哈世界气候峰会上, 与会国一致认为: 依据联合 国气候变化框架公约 (UNFCCC), 为了有效地应对全球气候变化, 可以在发展中国家实施积极的激励措施或 补偿措施,一方面可以减少由森林砍伐和退化造成的温室气体排放, 另一方面也可以增强森林的固碳能力, 即 $R E D D+{ }^{[8-10]}$ 。2013 年 11 月,在华沙《联合国气候变化框架公约》第十九次缔约方大会 $($ COP19) 暨《京都议定 书》第九次缔约方会议 $(\mathrm{CMP} 9)$ 上, 各方就 REDD+资金议题、REDD+行动方法指南议题、协调 REDD+行动支 持议题和 LULUCF (Land use, land use change and forestry) 相关技术问题议题展开深人讨论, 通过了与 REDD+ 相关的 7 个决定, 组成了 REDD+华沙框架。2015 年 12 月,《联合国气候变化框架公约》近 200 个缔约方在巴 黎气候变化大会上通过《巴黎协定》, 是继《京都议定书》后第二份有法律约束力的气候协议。2016 年 4 月 22 日,包括中国在内的 170 多个国家在纽约共同签署了这一协定, 承诺将全球气温升高幅度控制在 $2^{\circ} \mathrm{C}$ 的范围 之内 ${ }^{[11]}$ 。《巴黎协定》不仅为 2020 年后全球应对气候变化行动做出了安排, 同时也使该协定第五条涉及的 REDD+机制得到了国际法上的确认, 为国际社会进一步强化森林在应对气候变化问题上的效用, 以及发展中 
国家扩大森林经营, 实现低碳发展铺平了道路。为积极应对气候变化, 响应《巴黎协定》约定, 2020 年 9 月, 中国在联合国大会上向全世界宣布了 2030 年前实现碳达峰、2060 年前实现碳中和的目标 ${ }^{[11]}$, 而要实现这一 宏伟目标,显然离不开 REDD+行动框架。

毁林和森林退化不仅导致热带雨林地区碳储量减少和固碳能力降低,也将引起植被构成发生变化、土壤 侵蚀加剧、土地退化及水污染等系列效应, 从而对森林生态系统产生严重的负面影响。目前, 对 REDD+的碳 效应和生态效益进行评估已成为 REDD+研究的热点问题 ${ }^{[12-14]}$ 。鉴于此, 本研究以中国的西双版纳地区为研 究区域, 以毁林最严重的 1976-2007 年为 REDD+基线 ${ }^{[15-20]}$, 尝试对 REDD+的碳汇效益和生态效益进行系 统综合评估,并明确两者之间的关系。研究中, 基于卫星影像,并结合植被指数(NDVI), 提取了研究区的土地 利用变化信息。基于 IPCC 温室气体清单方法, 计算了研究区的森林碳储量变化。在此基础上,基于通用土 壤流失方程 (RUSLE) 和景观指数对包括土壤侵蚀和森林破碎化在内的 REDD+生态效益进行了核算。文中最 后对 REDD+的机制进行了探讨。

\section{1 数据和方法}

\section{1 研究区域}

西双版纳地区位于云南省南部边缘 $\left(21^{\circ} 09^{\prime}-\right.$ $22^{\circ} 36^{\prime} \mathrm{N}, 99^{\circ} 58^{\prime}-101^{\circ} 50^{\prime} \mathrm{E}$ ), 总面积约 $19674 \mathrm{~km}^{2}$ (图 1)。西双版纳拥有中国唯一保存面积最大、地球上 分布最北的热带雨林, 也是中国热带森林生态系统类型 最多的地区 ${ }^{[21]}$ 。近年来由于人口增加和人类活动加 剧,加之该区丰富的气候资源和适宜的地形条件, 橡胶 等热带经济林或作物的种植面积不断扩大, 导致森林砍 伐较严重, 森林破碎化加剧。森林砍伐引起了土地利 用/覆被变化, 不仅使西双版纳地区的植被碳楦量不断 减少, 碳储量分布模式也由随机离散分布逐渐趋向聚集 分布 ${ }^{[22]}$ 。此外, 森林景观结构也发生了显著变化。表 现为核心森林面积减少、斑块数量增加以及斑块间的孤 立程度提高等明显的森林破碎化现象,减弱了森林生态

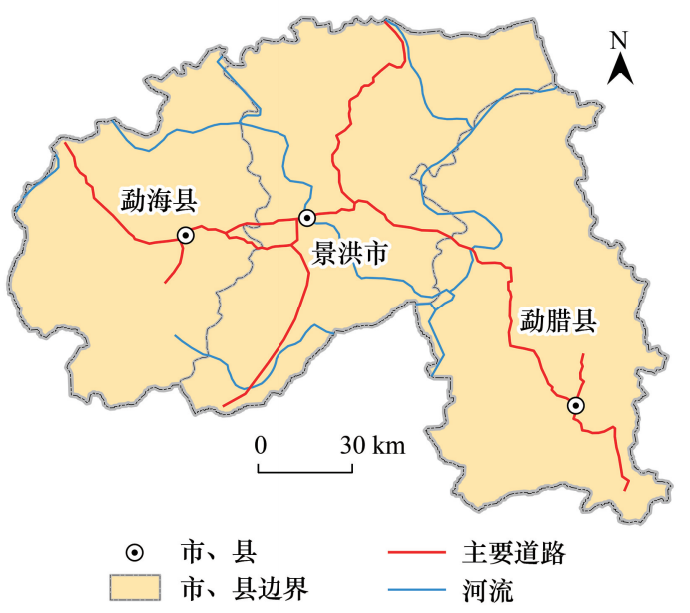

图 1 西双版纳全区图

Fig.1 Map of Xishuangbanna 系统服务功能, 对区内生态环境和生物多样性产生显著 影响 ${ }^{[23-24]}$ 。近年来, 土壤侵蚀问题也有所增长, 导致土地进一步退化, 森林和土壤对洪水的调控能力下降。 上述问题都会影响森林生态系统物质和能量的稳定循环, 进而对系统功能和稳定构成巨大威胁。

为界定 REDD+活动的参考时期和规模, REDD+框架设定了一种基准情形,即 REDD+基线。使用 REDD+ 基线可以评估在 REDD+减排增汇机制实施的情形下, 与不实施的情形相比会产生多少减排量, 从而为财政补 偿提供依据。过去的毁林时期通常被作为一个地区的 REDD+基线。1976-2007 年是西双版纳地区毁林最 严重的时期,因此,研究中以 1976-2007 年为 REDD+基线,对 REDD+的碳效应和生态效益进行评估。

\section{2 数据来源与处理}

本研究采用 1976、1992、1999、2007 年四期的遥感影像数据进行土地利用解译。其中,1976 年的 MSS 和 1992 年 TM 影像来源于美国地质调查局 (http://www. usgs. gov/) ; 1999 年和 2007 年的 ETM/TM 影像以及 Terra MODIS 影像均来源于中国科学院计算机网络信息中心地理空间数据云 (http://www.gscloud.cn)。2007 年的 ETM 数据使用地理空间数据云 (http://www.gscloud.cn) 提供的条带修复模型进行修复,修复方法为多影 像自适应局部回归。Terra MODIS 采用 16 天合成的 L3 数据产品 MOD13Q1。轨道号、日期、云量和数据来源 详见表 1 。 
表 1 遥感影像数据

Table 1 Remote sensing data

\begin{tabular}{lllll}
\hline $\begin{array}{l}\text { 数据类型 } \\
\text { Data type }\end{array}$ & $\begin{array}{l}\text { 轨道号 } \\
\text { Track number }\end{array}$ & $\begin{array}{l}\text { 日期 } \\
\text { Date }\end{array}$ & $\begin{array}{l}\text { 云量/\% } \\
\text { Cloudage }\end{array}$ & $\begin{array}{l}\text { 数据来源 } \\
\text { Data sources }\end{array}$ \\
\hline MSS & $\mathrm{p} 139 \mathrm{r} 45$ & $1976-02-24$ & 10 & USGS \\
& $\mathrm{p} 140 \mathrm{r} 44$ & $1976-02-25$ & 0 & \\
& $\mathrm{p} 140 \mathrm{r} 45$ & $1976-02-25$ & 10 & \\
TM & $\mathrm{p} 129 \mathrm{r} 45$ & $1992-09-01$ & 44 & GSCloud \\
& $\mathrm{p} 130 \mathrm{r} 45$ & $1992-11-11$ & 4.16 & \\
$\mathrm{p} 130 \mathrm{r} 44$ & $1992-11-11$ & 9.23 & \\
ETM & $\mathrm{p} 130 \mathrm{r} 44$ & $2007-03-26$ & 8.0 & 13.0 \\
& $\mathrm{p} 129 \mathrm{r} 45$ & $1999-09-29$ & 0.0 & \\
& & $2007-02-23$ & 0.0 & 0.0 \\
Terra MODIS & $\mathrm{p} 130 \mathrm{r} 45$ & $1999-12-25$ & 0.0 & - \\
Terra MODIS & $\mathrm{p} 130 \mathrm{r} 44$ & $1999-12-25$ & - & \\
\hline
\end{tabular}

MSS: 多光谱扫描仪 Multispectral scanner system; TM : 主题成像仪 Thematic mapper; ETM: 增强型主题成像仪 Enhanced thematic mapper; Terra MODIS: Terra 搭载的中分辨率成像光谱仪 Moderate resolution imaging spectroradiometer on terra; USGS: 美国地质调查局 United states geological survey; GSCloud: 地理空间数据云 Geospatial data cloud

根据研究区土地利用与覆被特点,本研究将土地利用/覆被分为 9 种类型: 天然林、灌木林、橡胶园、茶园、 旱地、水田、建设用地和其他用地。通过对研究区不同时期的卫星影像进行土地利用/覆被解译,可以追踪历 史上的毁林活动。根据联合国粮农组织 FAO 的定义, 毁林是指森林转换为其他土地利用方式的过程, 如转换 为新的农业用地、种植园用地,或者长期的林冠覆盖面积减少的过程。因此,研究中把天然林和灌木林的变化 都归于毁林的范畴。

\section{3 研究方法}

研究框架见图 2, 研究目标是分析 REDD+的碳效应和生态效益。首先基于卫星遥感影像,并结合植被指 数(NDVI)，提取出西双版纳地区的土地利用变化信息,这是分析碳效应和生态效益的基础。在碳效应方面, 利用 IPCC 方法,得到西双版纳地区森林碳储量变化,评估 REDD+机制的碳汇效益; 在生态效益方面,重点关 注森林破碎化与土壤侵蚀: 基于景观指数计算破碎化,基于通用土壤流失方程( RUSLE) 评估土壤侵蚀,并分 别分析他们与碳变化之间的关系。

\subsubsection{IPCC 温室气体清单计算方法}

根据《IPCC 土地利用、土地利用变化和林业优良做法指南》,碳库包括三部分, 即活生物量 ( LB) 碳库、死 有机质 (DOM) 碳库和土壤有机质 (SOM) 碳库; 其中,活生物量又包括地上部分生物量 ( AB) 和地下部分生物 量 $(\mathrm{BB})$, 死有机质又包括死木 $(\mathrm{DW})$ 和枯枝落叶 $(\mathrm{LT})$ 。

总碳库储量可以表示为:

$$
C_{\text {Total }}=C_{\mathrm{LB}}+C_{\mathrm{DOM}}+C_{\mathrm{soM}}
$$

式中, $C_{\mathrm{Total}}$ 为土地生态系统总碳库碳储量 $(\mathrm{t}) ; C_{\mathrm{LB}}$ 为活生物量碳储量 $(\mathrm{t}) ; C_{\mathrm{DOM}}$ 为死有机质碳储量 $(\mathrm{t}) ; C_{\mathrm{SOM}}$ 为土 壤有机质碳储量 $(\mathrm{t})$;

其中：

$$
C_{\mathrm{DOM}}=C_{D W}+C_{L T}
$$

式中, $C_{D W}$ 为死木碳储量 $(\mathrm{t}) ; C_{L T}$ 为枯枝落叶碳储量 $(\mathrm{t})$ 。

土地利用变化的碳效应评估是指按照以下指导方法从而计算出森林生态类型的活生物量碳库、死有机质 


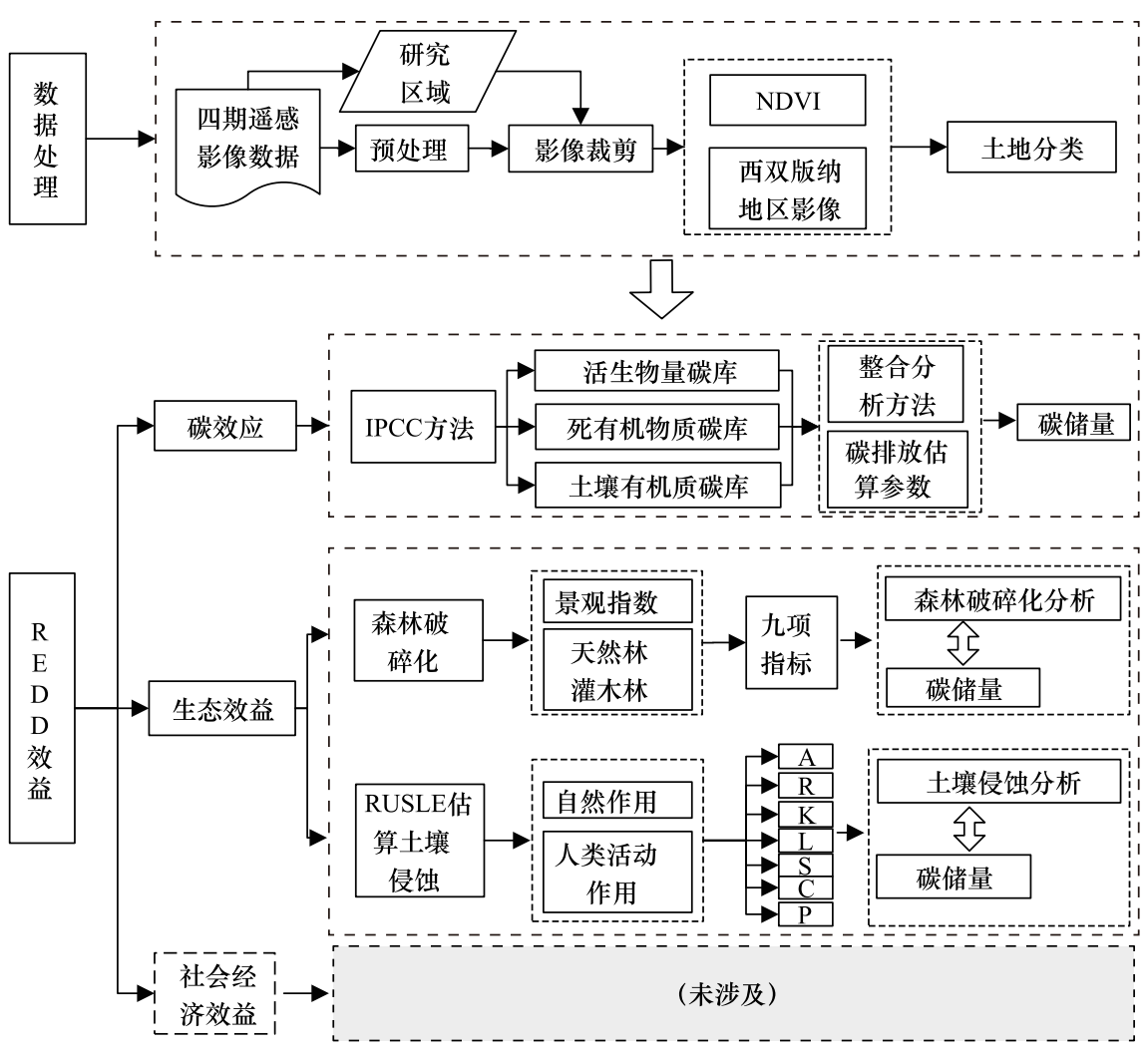

图 2 研究框架

Fig.2 Research framework

REDD+: 减少发展中国家因毁林和森林退化导致的温室气体排放和保持碳储量 Reducing emissions from deforestation and forest degradation in developing countries; NDVI: 归一化植被指数 Normalized difference vegetation index; IPCC: 政府间气候变化专门委员会 Intergovernmental panel on climate change; RUSLE: 修正的通用土壤流失方程 The revised universal soil loss equation

碳库和土壤碳库的年度变化。

即:

$$
\Delta C_{\text {Total }}=\Delta C_{L B}+\Delta C_{\mathrm{DOM}}+\Delta C_{\mathrm{SOM}}
$$

式中, $\Delta C_{\text {Total }}$ 为土地生态系统总碳库碳储量年际变化 $(\mathrm{t} / \mathrm{a}) ; \Delta C_{L B}$ 为活生物量碳储量年际变化 $(\mathrm{t} / \mathrm{a}) ; \Delta C_{\mathrm{DOM}}$ 为死有机质碳储量年际变化 $(\mathrm{t} / \mathrm{a}) ; \Delta C_{\mathrm{SOM}}$ 为土壤有机质碳储量年际变化 $(\mathrm{t} / \mathrm{a})$ 。

其中:死有机质碳储量年际变化又等于死木和枯枝落叶碳储量年际变化之和:

$$
\Delta C_{\mathrm{DOM}}=\Delta C_{D W}+\Delta C_{L T}
$$

式中, $\Delta C_{D W}$ 为死木碳储量年际变化 $(\mathrm{t} / \mathrm{a}) ; \Delta C_{L T}$ 为枯枝落叶碳储量年际变化 $(\mathrm{t} / \mathrm{a})$ 。

IPCC 方法需要在成本和测算结果的准确性之间进行权衡。为此, IPCC 在测算方法、参数和数据源方面 确定了三个层次的标准。对 REDD+机制来讲,允许测算结果存在一定的不确定性从而减少成本是十分必要 的。我国学者在陆地生态系统碳循环方面做了大量的工作,对西双版纳地区的植被、土壤碳储量和碳密度进 行了大量研究, 取得了丰硕的成果 ${ }^{[25-27]}$ 。张修玉等 ${ }^{[28]}$ 对西双版纳地区陆地植被碳储量进行了研究, 李红 梅 $^{[29]}$ 等对该地区土壤碳储量和碳密度进行了研究, 萧自位等 ${ }^{[30]}$ 、庞家平 ${ }^{[31]}$ 分别对西双版纳地区茶园、橡胶 林地区植被、土壤碳密度进行了研究,他们的研究为 IPCC 碳排放核算参数本地化提供了重要的参考,也为我 们核算 REDD+碳汇效益提供了依据。本文在综合国内大量相关研究的基础上,利用整合分析( Meta-analysis) 方法,对相关研究成果进行分类、综合,得到参数表 (表 2)。 
表 2 碳排放估算中采用的各种参数 $/\left(\mathrm{t} / \mathrm{hm}^{2}\right)$

Table 2 Parameters in carbon emissions evaluation

\begin{tabular}{lcccc}
\hline $\begin{array}{l}\text { 土地利用类型 } \\
\text { Land use type }\end{array}$ & $\begin{array}{c}\text { 土壤碳密度 } \\
\text { Soil carbon density }\end{array}$ & $\begin{array}{c}\text { 植被碳密度 } \\
\text { Vegetation carbon density }\end{array}$ & $\begin{array}{c}\text { 总碳密度 } \\
\text { Total carbon density }\end{array}$ & $\begin{array}{c}\text { 资料来源 } \\
\text { Source of data }\end{array}$ \\
\hline 天然林 Natural forest & 99.57 & 45.30211 & 144.8721 & {$[28-29]$} \\
灌木林 Shrubwood & 109.2 & 9.534 & 118.734 & {$[28-29]$} \\
茶园 Tea garden & 20.662 & 12.1768 & 32.8388 & {$[30]$} \\
橡胶园 Rubber plantation & 104.7 & 66.79645 & 171.4965 & {$[31-32]$} \\
荒草地 Wasteland & 60.6 & 4.935 & 65.535 & 103 \\
水田 Paddy field & 103 & 0 & 61.9 & {$[28,33]$} \\
早地 Dry land & 61.9 & 0 & {$[32]$} & {$[33]$} \\
\hline
\end{tabular}

\subsection{2 森林破碎化度量}

研究中采用景观指数来度量研究区的森林破碎化程度。景观指数通常用来测度土地覆被空间结构的组 成(数量、某一比例构成出现频率、景观中景观要素的多样性)和配置(景观中要素的分布和空间位置) 等 ${ }^{[34]}$ 。 景观指数分为斑块、类型、景观 3 个级别,本文选取天然林和灌木林两个类型级别景观指数和总体景观指数共 9 项指标来描述森林破碎化 (表 3 )。

表 3 景观指数选择

Table 3 Selected landscape index

\begin{tabular}{|c|c|c|c|c|c|}
\hline $\begin{array}{l}\text { 级别 } \\
\text { Rank }\end{array}$ & $\begin{array}{l}\text { 指标 } \\
\text { Index }\end{array}$ & $\begin{array}{l}\text { 描述 } \\
\text { Describe }\end{array}$ & $\begin{array}{l}\text { 级别 } \\
\text { Rank }\end{array}$ & $\begin{array}{l}\text { 指标 } \\
\text { Index }\end{array}$ & $\begin{array}{l}\text { 描述 } \\
\text { Describe }\end{array}$ \\
\hline \multirow[t]{5}{*}{ 类型 Type } & NP & 斑块数量 & 景观 Landscape & $\mathrm{NP}$ & 斑块数量 \\
\hline & AREA_MN & 斑块平均面积 & & AREA_MN & 斑块平均面积 \\
\hline & ENN_MN & 平均最近邻距离 & & COHESION & 景观内聚力指数 \\
\hline & SHAPE_MN & 平均形状指数 & & SHEI & Shannon's 均匀度指数 \\
\hline & & & & SHDI & Shannon's 多样性指数 \\
\hline
\end{tabular}

NP : Number of Patches; AREA_MN: Mean Patch Area; ENN_MN : Mean Euclidean Nearest-Neighbor Distance; SHAPE_MN : Mean Shape Index; COHESION : Patch Cohesion Index; SHEI: Shannon's Evenness Index; SHDI: Shannon's Diversity Index

森林破碎化指数的计算使用了马萨诸塞大学自然资源保护学院开发的 Fragstats 程序。研究中使用的土 地利用数据由遥感影像解译得到, 时间序列为 1976 年、1992 年、1999 年和 2007 年 4 期。

\subsection{3 基于 RUSLE 模型的土壤侵蚀评价}

本研究中,采用修正的通用土壤流失方程 (Revised Universal Soil Loss Equation,RUSLE) 来估算土壤侵蚀。 RUSLE 模型 ${ }^{[35]}$ 已被广泛地应用于评估自然和人类活动变化引起的土壤侵蚀变化。该模型揭示了在气候、土 壤、地形和土地覆被因素综合作用下,通过下渗和地表径流作用, 土壤侵蚀过程的发生和变化 ${ }^{[36]}$ 。RUSLE 计 算土壤侵蚀量的公式为:

$$
A=R \times K \times L \times S \times C \times P
$$

式中, $A$ 为单位面积年平均土壤流失量 $\left(\mathrm{t} / \mathrm{hm}^{2}\right) ; R$ 为降雨侵蚀力因子 $\left(\mathrm{MJ} \mathrm{mm} \mathrm{hm} \mathrm{hm}^{-2} \mathrm{~h}^{-1}\right) ; K$ 为土壤可蚀性因 子 $\left(\mathrm{t} \mathrm{h} \mathrm{MJ} \mathrm{mm}^{-1}\right) ; L$ 为坡长因子, $S$ 为坡度因子; $C$ 为植被覆盖与管理因子; $P$ 为水土保持措施因子。其中:

$R$ 反映降雨引起土壤分离和搬运的动力大小, 即降雨产生土壤侵蚀的潜在能力。本研究采用杨子生的方 法,使用雨季 $\left(5-10\right.$ 月) 累积降雨量估算降雨侵蚀因子 $R^{[37]}$ 。

$K$ 表示在单位降雨侵蚀指标下的土壤流失率, 此因子取决于土壤质地、有机质含量、土壤结构和土壤透水 性等。本文参考杨子生等 ${ }^{[37-39]}$ 的研究, 取其平均值 $0.326467 \mathrm{t} \mathrm{h} \mathrm{MJ}^{-1} \mathrm{~mm}^{-1}$ 。

$L$ 和 $S$ 代表地形因素对侵蚀的影响,研究中采用由美国太空总署(NASA) 和国防部国家测绘局 (NIMA) 联 合测量的 SRTM 数据, 坡长计算时使用到山脊线的距离作为近似值。由于 $L$ 和 $S$ 经常共同影响土壤流失, 因 
此, 将 $L$ 和 $S$ 结合起来, 作为一个复合因子( 即地形因子 $L S$ ) 进行综合测算, 参考杨子生的方法 ${ }^{[37]}$, 公式如下:

$$
L S=\left(\frac{L}{20}\right)^{0.24}\left(\frac{S}{5}\right)^{1.32}
$$

植被覆盖不同对土壤侵蚀的影响也不同 ${ }^{[40]}, C$ 用来衡量植被覆盖与植被管理对土壤侵蚀的影响。由于 NDVI 的差异可以表示植被覆盖度的不同,本研究中采用植被指数 NDVI 来估算 $C$ 值。利用欧洲土壤局提出 的方程,基于 NDVI 可以得到近似的 $C$ 因子:

$$
C=\exp \left[-\alpha \frac{\mathrm{NDVI}}{\beta-\mathrm{NDVI}}\right]
$$

式中, $\alpha \beta$ 为决定 NDVI-C 曲线形状的参数, 通常 $\alpha$ 的值取 $2, \beta$ 取 $1^{[41]}$ 。

$P$ 因子是采取水土保持措施后每单位面积土壤流失与顺坡耕作的比值,不同的土地利用类型由于管理方 式的不同会造成 $P$ 因子的差异。参考白晓松等 ${ }^{[42]}$ 的结果, 制定西双版纳地区 9 种不同土地类型的水土保持 措施因子(表 4)。

表 4 水土保持措施因子

Table 4 P Factor in RUSLE model

\begin{tabular}{cccccccccc}
\hline 天然林 & $\begin{array}{c}\text { 灌木林 } \\
\text { Natural } \\
\text { forest }\end{array}$ & Shrubwood & $\begin{array}{c}\text { 茶园 } \\
\text { Tea garden }\end{array}$ & $\begin{array}{c}\text { 橡胶园 } \\
\text { Rubber } \\
\text { plantation }\end{array}$ & $\begin{array}{c}\text { 荒草地 } \\
\text { Wasteland }\end{array}$ & $\begin{array}{c}\text { 水田 } \\
\text { Paddy } \\
\text { field }\end{array}$ & $\begin{array}{c}\text { 早地 } \\
\text { Dry land }\end{array}$ & $\begin{array}{c}\text { 建设用地 } \\
\text { Land used } \\
\text { for building }\end{array}$ & $\begin{array}{c}\text { 其他 } \\
\text { Else }\end{array}$ \\
\hline $\mathrm{P}$ & 1 & 1 & 0.6 & 0.8 & 1 & 0.01 & 0.55 & 0 & 0 \\
\hline
\end{tabular}

RUSLE: 修正的通用土壤流失方程 The Revised Universal Soil Loss Equation; P : 水土保持措施因子 the erosion control practice factor

\section{2 结果分析}

\section{1 土地利用变化}

由影像解译可得西双版纳地区 1976、1992、1999、2007 年的土地利用/覆被变化情况(图 3), 分析表明:在 此期间,土地利用/覆被发生了深刻的变化。从 1976-2007 共 32 年间,西双版纳天然林面积不断减少,而经 济林 (橡胶园和茶园) 面积持续增加, 且增加速度不断增大。1976 年, 该区天然林面积为 $1.35 \times 10^{6} \mathrm{hm}^{2}$, 占总面 积的 $68.62 \%$,到 2007 年,已减至 $8.60 \times 10^{5} \mathrm{hm}^{2}$ 。1976-2007 年间, 天然林面积平均每年减少 $1.17 \%$, 其中, 1976 - 1992 年间平均每年减少 $0.74 \%, 1992-1999$ 年间平均每年减少 $1.20 \%, 1999$ - 2007 年间平均每年减少 $2.64 \%$,减少速度不断加快。与此同时,橡胶园面积则以年均 $26.23 \%$ 速度增长, 1976-2007 年间,该区橡胶园 面积由 $2.58 \times 10^{4} \mathrm{hm}^{2}$ 增至 $2.36 \times 10^{5} \mathrm{hm}^{2}$, 净增 $2.10 \times 10^{5} \mathrm{hm}^{2}$ 。茶园的增长速度也在加快, 1976-1992 年间平均 每年增加 5.20× $10^{2} \mathrm{hm}^{2}, 1992-1999$ 年间平均每年增加 1.36 $\times 10^{3} \mathrm{hm}^{2}$, 而到 1999-2007 年间平均每年增加值

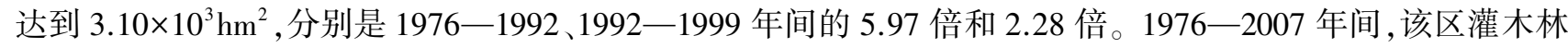
面积也在不断增加, 由 $2.23 \times 10^{5} \mathrm{hm}^{2}$ 增加至 $4.65 \times 10^{5} \mathrm{hm}^{2}$, 平均每年增加 $7.80 \times 10^{3} \mathrm{hm}^{2}$, 占总面积比重也由 $11.35 \%$ 增至 $23.64 \%$ 。荒草地、水田和旱地均呈现波动性变化,总体趋势较为稳定。

\section{2 土地利用变化引起的碳排放}

基于 IPCC 方法对西双版纳地区 1976-2007 年的碳储量进行计算,结果显示,该地区在这一时期内的碳 储量大幅度减少。1976-2007 年 32 年间, 西双版纳地区的总碳储量共减少了 $3.45 \times 10^{6} \mathrm{t}$, 其中, 1976-1992 年间平均每年减少 $0.54 \times 10^{4} \mathrm{t}, 1999-2007$ 年间平均每年减少 $1.60 \times 10^{4} \mathrm{t}$, 表明碳排放呈逐渐增加的趋势。 1976 年天然林的碳储量为 $1.96 \times 10^{8} \mathrm{t}$, 占总碳储量的 $78.24 \%$, 到 2007 年, 天然林碳储量减少至 $1.25 \times 10^{8} \mathrm{t}$, 占 总碳储量的 $50.52 \%$, 平均每年排放 $2.29 \times 10^{6} \mathrm{t}$ 碳。在低海拔地区, 大量天然林转化为灌木林、橡胶园和茶园。 毁林呈现出逐渐由低海拔、小坡度、南坡地区向高海拔、大坡度、北坡扩张的趋势。1976、1992、1999、2007年 不同土地利用类型碳储量变化情况见图 4。

\section{3 森林破碎化分析}

在景观动态变化过程中,天然林和灌木林的斑块数量、平均斑块面积、平均最近邻距离和平均形状指数均 


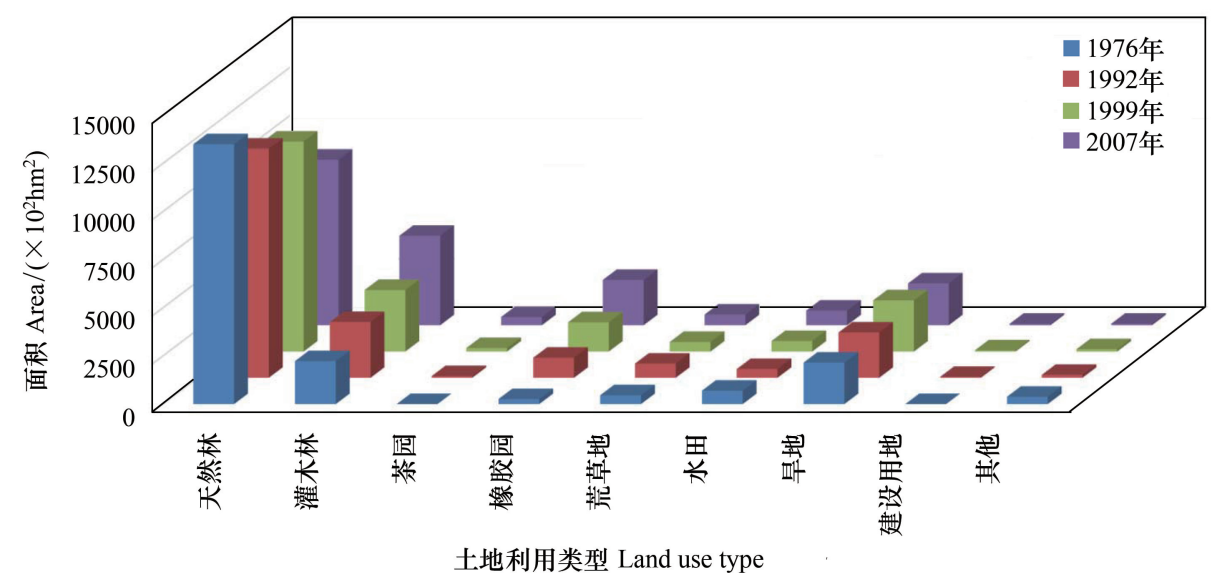

图 $31976 、 1992 、 1999 、 2007$ 年不同土地利用类型面积变化

Fig.3 Area change of different land use types in 1976, 1992, 1999 and 2007

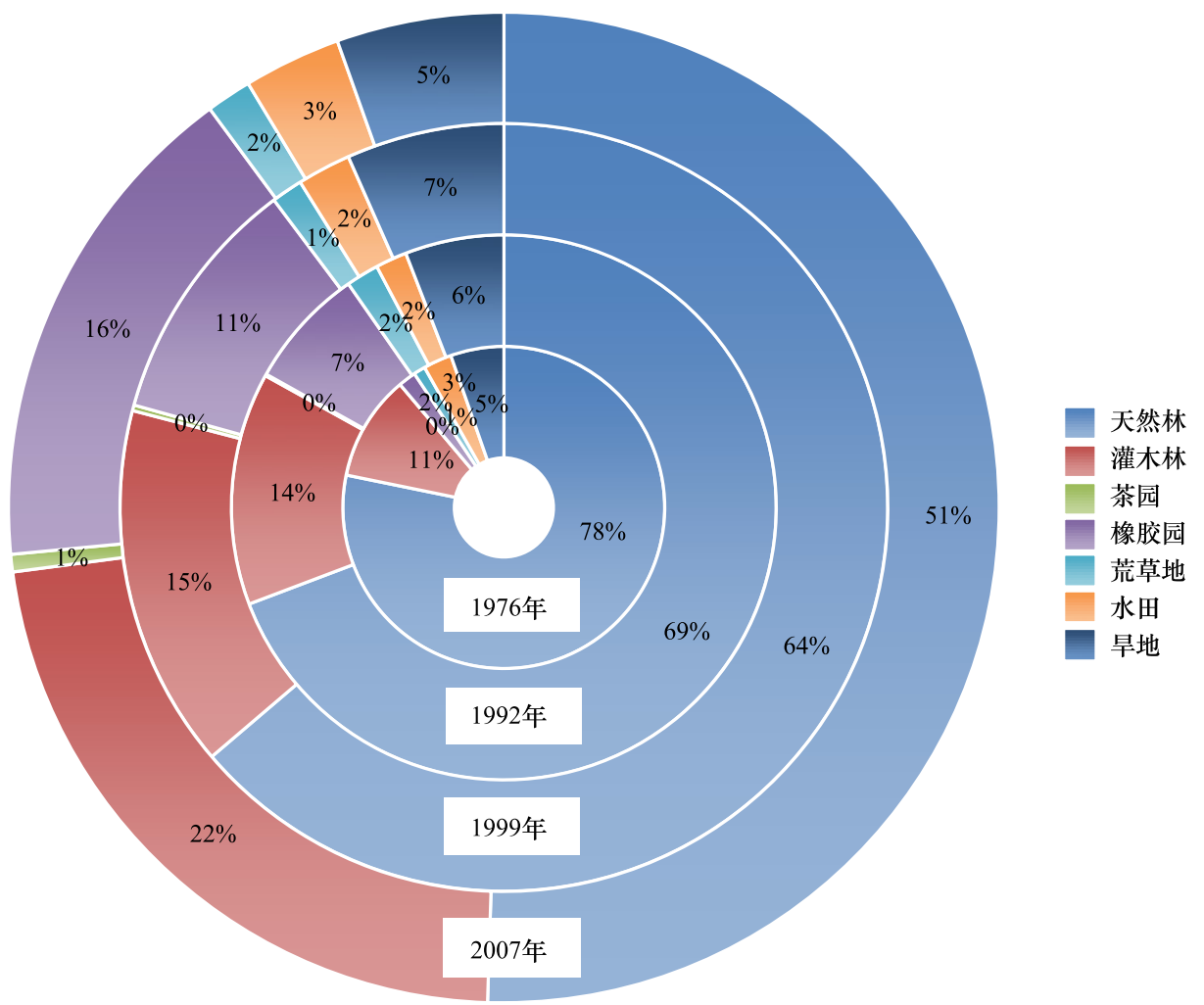

图 4 1976、1992、1999、2007 年不同土地利用类型碳储量变化

Fig.4 Carbon storage change of different land use types in 1976, 1992, 1999 and 2007

发生了明显变化。计算表明,天然林的 NP 不断增加,1976、1992、1999 年分别为 235、410 和 450,2007 年已增 加到 517, 为 1976 年的两倍多;AREA_MN 不断减小,1976、1992、1999 年分别为 5743.7、2860.7、2327 $\mathrm{hm}^{2}, 2007$ 年下降到 $1609.5 \mathrm{hm}^{2}$; ENN_MN 持续增长, 从 1976 年的 $849.5 \mathrm{~m}$, 增长到 1992 年的 $908.8 \mathrm{~m} 、 1999$ 年的 $951.8 \mathrm{~m}$ 和 2007 年的 $1063.7 \mathrm{~m}$ 。与此同时, 天然林的 SHAPE_MN 持续下降。这些说明天然林表现出了明显的破碎化 趋势。由于通常自然状态下的斑块形状较复杂, 而经过人类活动影响之后的斑块形状则会变得规整 ${ }^{[43]}$, 可见 
该时段内人类活动对天然林的影响是造成天然林破碎化程度加剧的重要原因。和天然林相反,灌木林的 NP、 ENN_MN 均表现出下降趋势, 而 AREA_MN 表现出上升趋势, 说明从 1976 年到 2007 年人为种植的灌木林景 观的聚集度增加。

研究中采用斑块数量、平均斑块面积、景观内聚力指数、Shannon 多样性指数和 Shannon 均一性指数来分 析研究区的整体景观结构。计算结果表明,1976-2007 年间,研究区的 NP 表现出明显的增长趋势。1976、 1992、1999 年分别为 5022、5566 和 5720,到 2007 年已增加到 6821。同时 AREA_MN 不断减小,由 1976 年的 $391.7 \mathrm{hm}^{2}$ 减小到 1992、1999、2007 年的 $353.54 \mathrm{hm}^{2} 、 343.97 \mathrm{hm}^{2}$ 和 $288.36 \mathrm{hm}^{2}$ 。研究区的 NP 的增加和 AREA_ MN 的减小,表明研究区已呈现明显的整体破碎化趋势。此外,COHESION 也由 1976 年的 99.34 下降到 1992 、 $1999 、 2007$ 年的 $98.85 、 98.59$ 和 97.23 , 整体呈现出降低趋势。

2.4 碳排放和森林破碎化之间的关系

本研究选取 1976、1992、1999、2007 年四个时间节点, 来探讨 1976-2007 年间研究区碳排放和森林破碎 化之间的关系。图 5 显示了几个时间段的碳储量和森林破碎化指数的百分比变化情况。由图 5 可知, 以 1976 年的数据为基准,与 1976 年相比,1992 年的碳储量减少了 $1.7 \%$,到 1999 、2007 年分别减少了 $3.38 \%$ 和 $8.16 \%$ 。与此相对应的是, 1976-2007 年 32 年间, NP 增加了 $8.16 \%$, SHDI 和 SHEI 分别增加了 51.39\% 和 $34.07 \%$; 同时,AREA_MN 和 COHESION 分别减小了 $26.26 \%$ 和 $2.13 \%$ 。以上数据表明, 研究区森林砍伐引起 的土地利用/覆被变化, 不仅导致碳储量的减少, 森林景观结构也发生了显著变化, 破碎化趋势明显, 二者变化 相一致。

2.5 碳排放与土壤侵蚀之间的关系

研究中使用 RUSLE 模型对研究区土壤侵蚀进行了 核算。结果表明: 1999-2007 年间,西双版纳地区全年 土壤侵蚀总量由 $6.44 \times 10^{7} \mathrm{t}$ 增加到 $8.24 \times 10^{7} \mathrm{t}$, 年均增速 为 $3.12 \%$; 全区平均土壤侵蚀模数由 $32.9 \mathrm{t} / \mathrm{hm}^{2}$ 增加到 $42.08 \mathrm{t} / \mathrm{hm}^{2}$; 侵蚀模数 $80 \mathrm{t} / \mathrm{hm}^{2}$ 以上的严重侵蚀区从 $2.31 \times 10^{5} \mathrm{hm}^{2}$ 增加到 $2.78 \times 10^{5} \mathrm{hm}^{2}$ 。以上数据说明 1999-2007 年间, 西双版纳地区土壤侵蚀越来越严重 (图 6)。

为了分析土壤侵蚀与碳排放之间的关系, 按 1999 年和 2007 年的土壤侵蚀等级 (轻度侵蚀、中度侵蚀、重 度侵蚀、极重度侵蚀和剧烈侵蚀) 对碳排放进行了统计 (图 6)。结果显示,土壤侵蚀剧烈的区域,其平均碳排 放也相对较高。1999 年到 2007 年间, 剧烈侵蚀区域的 平均碳排放是轻度侵蚀区域的 6 倍多。由此可见,随着 碳储量的减少, 区域的土壤侵蚀量呈现出增加的趋势, 碳排放和土壤侵蚀呈现出强烈的相关性。

\section{3 讨论和结论}

西双版纳地区的森林生态系统作为中国重要的碳 库, 维持其生态系统的稳定, 增加碳汇, 减少碳排放, 对

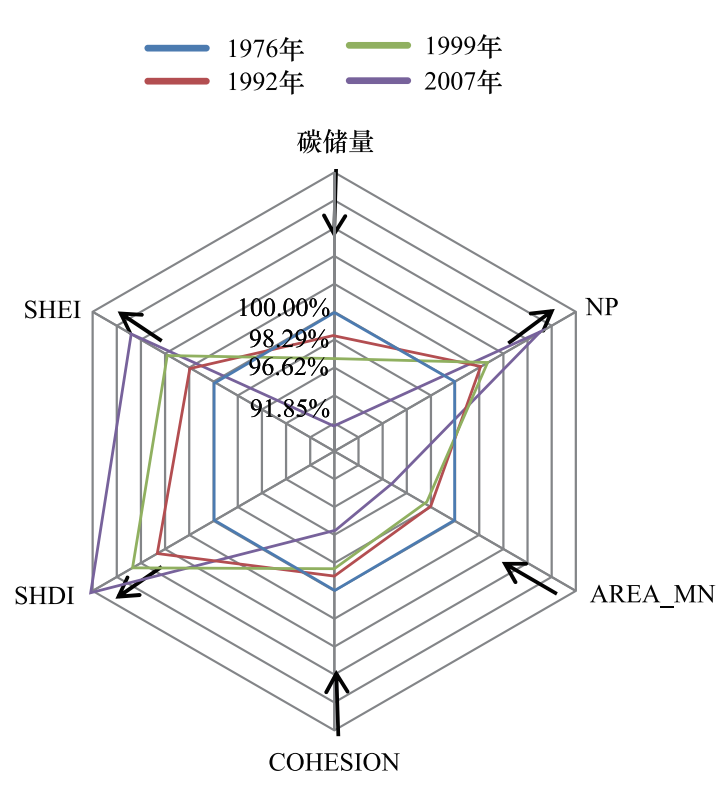

图 5 碳储量和森林破碎化百分比变化图

Fig.5 Relationship between carbon storage change and fragmentation in 1976, 1992, 1999 and 2007

SHEI: Shannon 均匀度指数 Shannon's Evenness Index; SHDI: Shannon 多样性指数 Shannon's Diversity Index; COHESION : 景观 内聚力指数 Patch Cohesion Index; AREA_MN: 平均斑块面积 Mean Patch Area; NP: 斑块数量 Number of Patches 中国落实《巴黎协定》约定, 努力实现 2060 年前碳中和的目标起着重要作用。同时, 对该区毁林导致的土地 覆被变化的碳效应和生态效益进行系统综合评估,可为 REDD+研究提供重要借鉴。

（1）1976-2007 年, 由于森林砍伐和退化, 西双版纳地区天然林碳储量从占总碳储量的 $78.24 \%$ 减少至 


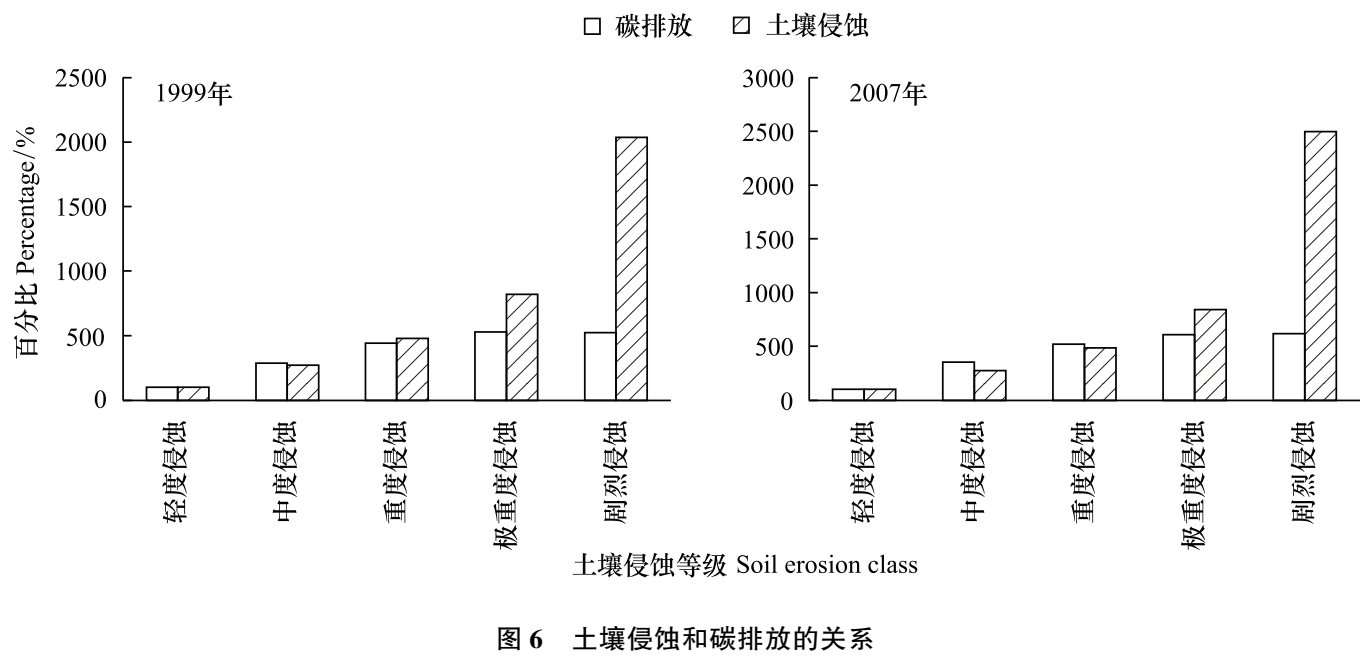

Fig.6 Relationship between carbon emissions and soil erosion

$50.52 \%$,这是造成该区碳储量减少的主要原因。西双版纳地区毁林的主要原因是发展压力,如: 人口增加、经 济发展和居民生活水平提升等。但近年来,随着中国生态保护工程的实施, 执法力度进一步加强, 西双版纳地 区非法毁林现象已呈减少趋势; 同时, 通过 “退耕还林” 等行动, 西双版纳地区进一步增加了热带雨林的碳储 量, 保护了雨林生物多样性 ${ }^{[4-47]}$ 。鉴于生态保护工程的成果, 在 REDD+林业谈判中, 中国可坚持如下立场: 在 REDD+之内, 强调造林和再造林的森林碳汇信用, 以体现中国生态保护工程的效果; 在 REDD+之外, 应积 极呼吁设立森林保护奖励机制, 用于激励在森林保护上作出重要贡献的发展中国家和地区,如西双版纳地区。

(2) 在西双版纳地区开展 REDD+项目,需要国际组织、国家、当地政府、当地居民的紧密配合, 还需要外 部资金的紧密合作。而 REDD+的核心是利用市场机制来鼓励因森林砍伐导致的温室气体排放的国家减少森 林破坏和防止森林退化, 同时允许这些国家通过碳市场获利。因此, 在对外方面, 中国需要表明发达国家有义 务和责任帮助发展中国家, 发达国家须提供充足的资金,通过技术培训提升发展中国家的能力,减少毁林和森 林退化导致的碳排放,例如在西双版纳地区。在对内方面, 中国可以考虑开放碳市场中的志愿市场, 从而在西 双版纳地区引入森林生态有偿服务机制。同时, 中国也可以先让一些企业和发达地区对西双版纳地区的森林 保护进行投资, 以保护西双版纳地区的森林和生态环境, 通过增强森林碳储量提高森林治理在西双版纳地区 发展中的作用。

(3) 研究发现, 西双版纳地区的土壤侵蚀与碳储量密切相关。同时,随着天然林被砍伐,森林破碎化迅速 增加, 对西双版纳地区的生物多样性造成严重威胁 ${ }^{[48-52]}$ 。这些结果说明: 通过停止毁林和森林退化, REDD+ 政策的实施可以给西双版纳地区带来高的生态效益。在天然林方面,可以帮助恢复和改善林分的结构,增加 西双版纳地区生物群落的栖息地和多样性;在商品林方面,通过加强西双版纳地区的采伐与运输管理,可以提 高森林的恢复力,有利于生物多样性的保护。

致谢:感谢河南大别山森林生态系统国家野外科学观测研究站的支持。

参考文献 (References) :

[ 1 ] Solomon S, Qin D, Manning M, Chen Z, Marquis M, Averyt K B, Tignor M, Miller H L. Climate Change 2007: the Physical Science Basis: Contribution of Working Group I to the Fourth Assessment Report of the IPCC. Cambridge, United Kingdom: Cambridge University Press, 2007.

[ 2 ] Ramankutty N, Gibbs H K, Achard F, DeFries R, Foley J A, Houghton R A. Challenges to estimating carbon emissions from tropical deforestation. Global Change Biology, 2007, 13(1): 51-66.

[ 3 ] Martinuzzi S, Gould W A, Gonzalez O M R, Robles A M, Maldonado P C, Perez-Buitrago N, Caban J J F. Mapping tropical dry forest habitats 
integrating Landsat NDVI, IKONOS imagery, and topographic information in the Caribbean Island of Mona. Revista de Biologia Tropical, 2008, 56 (2): 625-639.

[ 4 ] Murray B C, McCarl B A, Lee H C. Estimating leakage from forest carbon sequestration programs. Land Economics, 2004, 80(1): 109-124.

[ 5 ] Herold M, Johns T. Linking requirements with capabilities for deforestation monitoring in the context of the UNFCCC-REDD process. Environmental Research Letters, 2007, 2(4) : 045025.

[6]雪明, 武曙红, 程书强. 我国 REDD+行动的测量、报告和核查体系. 林业科学, 2012, 48(3): 128-131.

[ 7 ] Lu H L, Liu G F. Distributed land use modeling and sensitivity analysis for REDD+. Land Use Policy, 2013, 33(4) : 54-60.

[ 8 ] 毕欣欣, 李玉娥, 高清竹, 万运帆, 秦晓波. 减少发展中国家毁林及森林退化排放 (REDD) 的各方观点及对策建议. 气候变化研究进展, 2010, 6(1): 65-69.

[ 9 ] Angelsen A. Moving Ahead with REDD: Issues, Options and Implications. Bogor, Indonesia: Center for International Forestry Research (CIFOR), 2008.

[10］盛济川, 吴优. 发展中五国森林减排政策的比较研究——基于结构变量“REDD+机制”政策评估方法. 中国软科学, 2012，(9)：175-183.

[11] 解振华. 坚持积极应对气候变化战略定力继续做全球生态文明建设的重要参与者、贡献者和引领者一一纪念《巴黎协定》达成五周年. 中 国环境报, 2020-12-14(002).

[12] Burgess N D, Bahane B, Clairs T, Danielsen F, Dalsgaard S, Funder M, Hagelberg N, Harrison P, Haule C, Kabalimu K, Kilahama F, Kilawe E, Lewis S L, Lovett J C, Lyatuu G, Marshall A R, Meshack C, Miles L, Milledge S A H, Munishi P K T, Nashanda E, Shirima D, Swetnam R D, Willcock S, Williams A, Zahabu E. Getting ready for REDD+ in Tanzania: a case study of progress and challenges. Oryx, 2010, 44(3): 339-351.

[13］袁梅, 谢晨, 黄东. 减少毁林及森林退化造成的碳排放 (REDD) 机制研究的国际进展. 林业经济, 2009, (10): 23-28.

[14] 黄小荣, 间鼎羽. 减少森林砍伐和退化机制中的碳评估探讨. 世界林业研究, 2011, 24(5)：71-76.

[15] Xiao C W, Li P, Feng Z M. A renormalized modified normalized burn ratio (RMNBR) index for detecting mature rubber plantations with Landsat-8 OLI in Xishuangbanna, China. Remote Sensing Letters, 2019, 10(3): 214-223.

[16] 翟德利, 许建初, 戴志聪. 云南西双版纳地区森林转型特征(英文). 植物分类与资源学报, 2015, 37 (1): 93-98.

[17］刘晓娜, 封志明, 姜鲁光. 中老缅泰“黄金四角”地区土地利用与土地覆被变化研究进展. 地理科学进展, 2013, 32(2)：191-202.

［18］刘晓娜，封志明，姜鲁光，张景华. 西双版纳土地利用/土地覆被变化时空格局分析. 资源科学, 2014, 36(2)：233-244.

[19］廖谌婳，封志明，李鹏，张景华. 中老缅泰交界地区土地利用变化信息挖掘与国别对比. 自然资源学报，2015，30(11)：1785-1797.

[20] Lu S Q, Zhang C R, Lu H L. Spatio-temporal dynamics of shifting cultivation in Upland Myanmar using time series images and implications for REDD +//Proceedings of SPIE 10777, Land Surface and Cryosphere Remote Sensing IV. Honolulu, Hawaii, United States: SPIE, 2018: 1077700.

[21] 何承刚, 冯彦, 杨燕平. 西双版纳林地景观演变过程及其驱动力分析. 云南地理环境研究, 2008, 20(5)：12-17.

[22] 张修玉, 宋巍巍, 许振成, 张恒军, 曾凡棠. 西双版纳区域植被碳储量时空演变特征. 生态环境学报, 2013, 22(7)：1105-1110.

[23] 王云花. 西双版纳地区水文特性分析. 水文, 2003, 23(4) : 55-59.

[24] 曹智伟. 西双版纳主干公路沿线土地利用变化时空格局研究 [D]. 西双版纳: 中国科学院研究生院 (西双版纳热带植物园), 2006.

[25] 李增加. 西双版纳土地利用/覆盖变化及其气候效应研究 $[D]$. 西双版纳: 中国科学院研究生院 (中国科学院西双版纳热带植物 园), 2008.

[26] 吕晓涛. 西双版纳热带季节雨林碳储量的研究 [D]. 西双版纳: 中国科学院研究生院 (西双版纳热带植物园), 2006.

[27] 李红梅, 马友金金, 郭宗峰, 刘文俊, 张一平. 西双版纳森林植被的碳败量及影响因素分析. 福建林学院学报, 2005, 25(4): 368-372.

[28] 张修玉, 许振成, 王俊能, 宋巍巍, 秦建桥, 胡习邦, 张婉璐, 邹洁. 西双版纳森林植被碳储量动态与增汇潜力研究. 生态环境学报, $2011,20(3)$ : 397-402.

[29］李红梅, 马友金鍂宗峰, 刘文俊. 西双版纳土壤有机碳储量及空间分布特征//推进气象科技创新加快气象事业发展一一国气象学会 2004 年年会论文集(下册). 北京, 中国: 气象出版社, 2004: 565-572.

[30］萧自位, 王丽娟, 毛加梅, 朱兴正, 王小李, 郑丽, 唐建维. 西双版纳不同林茶复合生态系统碳储量. 生态学杂志, 2012, 31 (7)： $1617-1625$.

[31] 庞家平. 西双版纳橡胶林的碳储量及其分配格局 [D ]. 西双版纳: 中国科学院研究生院 (西双版纳热带植物园), 2009.

[32] 沙丽清. 西双版纳热带季节雨林、橡胶林及水稻田生态系统碳储量和土壤碳排放研究 [D]. 西双版纳: 中国科学院研究生院 (西双版纳热 带植物园), 2008.

［33］解宪丽, 孙波, 周慧珍, 李忠佩. 不同植被下中国土壤有机碳的储量与影响因子. 土壤学报, 2004, 41(5): 687-699.

[34] Giordano F, Marini A. A landscape approach for detecting and assessing changes in an area prone to desertification in Sardinia (Italy). International Journal of Navigation and Observation, 2008, 2008: 549630. 
[35] 陈云明, 刘国涁, 郑粉莉, 张卫. RUSLE 侵蚀模型的应用及进展. 水土保持研究, 2004, 11(4) : 80-83.

[36] Renard K G, Foster G R, Weesies G A, McCool D K, Yoder D C. Predicting Soil Erosion by Water: A Guide to Conservation Planning with the Revised Universal Soil Loss Equation (RUSLE). Washington DC.: U.S. Government Printing Office, 1997.

[37] 杨子生. 云南省金沙江流域土壤流失方程研究. 山地学报, 2002, 20(S1)：1-9.

[38］彭建, 李丹丹, 张玉清. 基于 GIS 和 RUSLE 的滇西北山区土壤侵蚀空间特征分析一一以云南省丽江县为例. 山地学报, 2007，25(5): 548-556.

[39] 刘文耀. 云南昭通盆地降雨侵蚀性与土壤可蚀性的初步研究. 云南地理环境研究, 1999, 11(2): 76-82.

[40] Renard K G, Foster G R, Weesies G A, Porter J P. RUSLE: revised universal soil loss equation. Journal of Soil and Water Conservation, 1991 , 46 (1) : 30-33.

[41] Van der Knijff J M, Jones R J A, Montanarella L. Soil Erosion Risk Assessment in Italy. EUR 19022EN. Luxembourg: Office for Official Publications of the European Communities, 1999.

[42］白晓松. 基于 RUSLE 的北方山区土壤侵蚀定量研究与生态适宜性评价 [D]. 保定: 河北农业大学, 2010.

[43] 何承刚, 冯彦, 李英. 西双版纳土地利用/覆被变化及其景观格局特征分析. 云南地理环境研究, 2009, 21(4) : 51-57.

[44] Singh D, Slik J W F, Jeon Y S, Tomlinson K W, Yang X D, Wang J, Kerfahi D, Porazinska D L, Adams J M. Tropical forest conversion to rubber plantation affects soil micro- \& mesofaunal community \& diversity. Scientific Reports, 2019, 9(1) : 5893.

[45] Lu H L, Liu G F, Zhang C R, Okuda T. Approaches to quantifying carbon emissions from degradation in pan - tropic forests - implications for effective REDD monitoring. Land Degradation \& Development, 2020, 31(15) : 1890-1905.

[46] Luo Y J, Wang X K, Ouyang Z Y, Lu F, Feng L G, Tao J. A review of biomass equations for China's tree species. Earth System Science Data, $2020,12(1): 21-40$.

[47] 张春霞, 谢佰承, 贾松伟. 土壤侵蚀对土壤有机碳库去向的影响. 安徽农业科学, 2008, 36(31) : 13735-13736, 13742-13742.

[48] Liu P, Li W W, Yu Y, Tang R C, Guo X M, Wang B, Yang B, Zhang L. How much will cash forest encroachment in rainforests cost? A case from valuation to payment for ecosystem services in China. Ecosystem Services, 2019, 38: 100949.

[49] Miller F P, McGregor A. Rescaling political ecology? World regional approaches to climate change in the Asia Pacific. Progress in Human Geography, 2020, 44(4) : 663-682.

[50] Lu H L, Liu G F, Okuda T, Zhang C R. Marginal abatement cost curves for REDD+ in Kalimantan, Indonesia and the potential role of cost-saving plantations. Environmental Research Letters, 2018, 13(7) : 075006.

[51］冯瑞芳, 杨万勤, 张健. 人工林经营与全球变化减缓. 生态学报, 2006, 26(11): 3870-3877.

[52] 卢鹤立, 刘桂芳. REDD+集成评估模型构建与情景模拟. 中国科学: 地球科学, 2014, 44(7): 1588-1599. 